\title{
Genome-wide association study for endocrine fertility traits using single nucleotide polymorphism arrays and sequence variants in dairy cattle
}

\author{
A. M. M. Tenghe, ${ }^{*} \neq \dagger^{1}$ A. C. Bouwman, ${ }^{*}$ B. Berglund, $\ddagger$ E. Strandberg, $\ddagger$ D. J. de Koning, $\ddagger$ and R. F. Veerkamp $†$ \\ ${ }^{*}$ Animal Breeding and Genomics Centre, Wageningen UR Livestock Research, PO Box 338, 6700 AH Wageningen, the Netherlands \\ †Animal Breeding and Genomics Centre, Wageningen University, PO Box 338, $6700 \mathrm{AH}$ Wageningen, the Netherlands \\ fDepartment of Animal Breeding and Genetics, Swedish University of Agricultural Sciences, PO Box 7023, SE-750 07 Uppsala, Sweden
}

\begin{abstract}
Endocrine fertility traits, which are defined from progesterone concentration levels in milk, are interesting indicators of dairy cow fertility because they more directly reflect the cows own reproductive physiology than classical fertility traits, which are more biased by farm management decisions. The aim of this study was to detect quantitative trait loci (QTL) for 7 endocrine fertility traits in dairy cows by performing a genomewide association study with 85k single nucleotide polymorphisms (SNP), and then fine-map targeted QTL regions, using imputed sequence variants. Two classical fertility traits were also analyzed for QTL with $85 \mathrm{k}$ SNP. The association between a SNP and a phenotype was assessed by single-locus regression for each SNP, using a linear mixed model that included a random polygenic effect. A total of 2,447 Holstein Friesian cows with 5,339 lactations with both phenotypes and genotypes were used for association analysis. Heritability estimates ranged from 0.09 to 0.15 for endocrine fertility traits and 0.03 to 0.10 for classical fertility traits. The genome-wide association study identified 17 QTL regions for endocrine fertility traits on Bos taurus autosomes (BTA) 2, 3, 8, 12, 15, 17, 23, and 25. The highest number (5) of QTL regions from the genome-wide association study was identified for the endocrine trait "proportion of samples with luteal activity." Overlapping QTL regions were found between endocrine traits on BTA 2, 3, and 17. For the classical trait calving to first service, 3 QTL regions were identified on BTA 3, 15 , and 23, and an overlapping region was identified on BTA 23 with endocrine traits. Fine-mapping target regions for the endocrine traits on BTA 2 and 3 using imputed sequence variants confirmed the QTL from the genome-wide association study, and identified several associated variants that can contribute to an index of markers for genetic improvement of fertility. Several
\end{abstract}

Received October 16, 2015.

Accepted March 15, 2016.

${ }^{1}$ Corresponding author: amabel.tenghe@wur.nl potential candidate genes underlying endocrine fertility traits were also identified in the target regions and are discussed. However, due to high linkage disequilibrium, it was not possible to specify genes or polymorphisms as causal factors for any of the regions.

Key words: quantitative trait loci, milk progesterone, dairy cattle, fertility

\section{INTRODUCTION}

Genome-wide association studies (GWAS) have identified thousands of SNP across the cattle genome associated with important economic traits (Hu et al., 2016). Previous studies that have attempted to locate QTL for reproductive performance in dairy cattle have used mostly classical fertility traits, see Khatkar et al. (2004) for a review, and the cattle QTL database (Hu et al., 2016) for more recent studies. Endocrine fertility traits defined from progesterone concentration levels in milk have been suggested as alternative indicators for dairy cow fertility, because they more directly reflect a cow's reproductive physiology and are less influenced by farm management decisions (Bulman and Lamming, 1978; Darwash et al., 1999), compared with classical fertility traits, which are defined from calving data and insemination records. Hence, endocrine fertility traits might be more useful to detect fertility QTL. In addition, endocrine fertility traits seem to be more heritable than classical traits (Veerkamp et al., 2000; Petersson et al., 2007; Tenghe et al., 2015), but few GWAS studies have been performed for endocrine fertility traits (Berry et al., 2012).

Most of the genetic variants detected in GWAS are not the causal mutations for the traits, but in linkage disequilibrium (LD) with these causal polymorphisms. This is so mainly because the marker panels used in most of the studies only represent a small fraction of the common variants segregating in the population. However, advances in next generation sequencing techniques have led to sequencing a large number of animals in cattle. Also, imputation techniques offer the possibility to reliably impute genotyped animals 
to sequence variants (Browning and Browning, 2009). The advantage of using sequence data over SNP arrays for GWAS arises from the expectation that there will be higher precision in detecting QTL because the data are expected to include the causal variant, and there is less dependence on population LD (Meuwissen and Goddard, 2010; Daetwyler et al., 2014; Druet et al., 2014). Furthermore, recent studies have shown that the precision of mapped QTL can be increased by the use of sequence data (Sahana et al., 2014; Höglund et al., 2014a, 2015).

Genomic prediction helps to select breeding animals for the next generation more accurately at an early age. In addition to revealing the genetic architecture that underlies the physiological and biological process of female reproduction, detected QTL could also be practically applied to genomic selection schemes to improve fertility. The introduction of high-density SNP arrays like the $777 \mathrm{k}$ did not increase accuracy of genomic predictions in cattle substantially ( $\mathrm{Su}$ et al., 2012; VanRaden et al., 2013), one of the reasons being the increase in the number of unknown parameters to be estimated with high-density data. However, Meuwissen and Goddard (2010) demonstrated in simulations that genomic predictions based on sequence data were up to $40 \%$ more accurate than predictions based on $\sim 30 \mathrm{k}$ SNP, because the causal mutations were used in prediction. Furthermore, in another simulation study, Druet et al. (2014) showed that, if the minor allele frequency of QTL is very low, genomic predictions from imputed sequence data can have up to $20 \%$ advantage in accuracy of genomic predictions from SNP panels. If the causal mutations influencing female fertility are detected, this information could be included in genomic prediction models where additional weight is put on the regions that influence female fertility; this would especially improve predictions over generations.

The aim of this study was to detect QTL for 7 endocrine fertility traits in dairy cows by performing a GWAS with 85k SNP, and then fine-map targeted QTL regions using imputed sequence variants. Two classical fertility traits were also analyzed for QTL with $85 \mathrm{k}$ SNP.

\section{MATERIALS AND METHODS}

\section{Animal Population and Phenotypes}

The data consisted of in-line progesterone (P4) records from 14 commercial herds in the Netherlands, and manually collected P4 records of 4 experimental herds from Wageningen UR Livestock Research, the Netherlands; Teagasc, Moorepark, Ireland; Scottish Agricultural College, United Kingdom; and the Jälla herd of Swedish University of Agricultural Science. In total, phenotypic data were available for 2,447 Holstein cows with 5,339 lactations.

A detailed description of the experimental treatments imposed on animals in the different experimental herds, procedures for milk sampling and $\mathrm{P} 4$ level measuring have been given in Veerkamp et al. (2000), Horan et al. (2005), Petersson et al. (2006), and Pollott and Coffey (2008). In brief, milk sampling for P4 measurement was undertaken twice a week at the experimental herds in Sweden and the Netherlands, and thrice a week in Ireland and the United Kingdom. In the commercial herds, milk sampling, measuring, and recording of P4 level were performed by the Herd Navigator (HN, DeLaval Intl., Tumba, Sweden). Sampling frequency on the commercial herds is based on a biological model (Friggens et al., 2008), but on average undertaken every $2 \mathrm{~d}$.

For each lactation, endocrine fertility traits were defined using $\mathrm{P} 4$ records as described in Tenghe et al. (2015) as follows: (1) commencement of luteal activity (C-LA) as the number of days between calving and first day on which milk $\mathrm{P} 4$ level was elevated $(\geq 5 \mathrm{ng} /$ $\mathrm{mL})$; (2) proportion of samples with luteal activity (PLA) as the number of $\mathrm{P} 4$ records with luteal activity ( $\mathrm{P} 4$ level $\geq 5 \mathrm{ng} / \mathrm{mL}$ ), divided by total number of $\mathrm{P} 4$ records in the period from 25 to 60 DIM; (3) luteal activity during first 60 DIM (LA60) as the presence $($ LA60 $=1)$ or absence $($ LA60 $=0)$ of luteal activity between 25 and 60 DIM; (4) commencement of luteal activity to first service (CLAFS) as the interval from the first day of elevated $\mathrm{P} 4$ level $(\geq 5 \mathrm{ng} / \mathrm{mL})$, fitting the luteal activity criteria, to day of first service; (5) first luteal phase length (LPL) as the interval from the first day of elevated P4 level $(\geq 5 \mathrm{ng} / \mathrm{mL})$ to the last consecutive day of elevated $\mathrm{P} 4$ level $(\geq 5 \mathrm{ng} / \mathrm{mL})$; (6) length of inter-luteal interval (ILI) as the interval from the first day of decreased $\mathrm{P} 4$ level $(<5 \mathrm{ng} / \mathrm{mL})$ following the luteal phase, and the last consecutive day of decreased P4 level $(<5 \mathrm{ng} / \mathrm{mL})$; and (7) length of first inter-ovulatory interval (IOI) as the interval from the first day of elevated $\mathrm{P} 4$ level $(\geq 5 \mathrm{ng} / \mathrm{mL})$ of one estrus cycle to the first day of elevated P4 level ( $\geq 5 \mathrm{ng} /$ $\mathrm{mL}$ ) of the following estrus cycle. In defining the endocrine fertility traits, a set of restrictions was applied to periods of nonsampling of $\mathrm{P} 4$ records that might occur during a lactation period. When a gap was cow-specific, that is, when the cows lactation had no P4 samples for more than $7 \mathrm{~d}$, the following restrictions were applied: (1) if the gap occurred 1 or more days before C-LA, and the gap duration was less than $15 \mathrm{~d}$, all traits were retained, otherwise all traits were excluded; $(2)$ if the gap occurred at least $25 \mathrm{~d}$ after C-LA, all traits were retained, otherwise all traits were excluded except C-LA. 
When a gap was herd-specific, the following restrictions were applied to all lactations on that herd; for each lactation, when a gap of 3 or more days occurred 1 or more days before C-LA and P4 values were low after the gap, C-LA and all traits were retained, whereas when a gap of 3 or more days occurred after C-LA, the following restrictions where applied: (a) LPL was retained if the gap occurred at least $25 \mathrm{~d}$ after C-LA; (b) ILI was retained if gap occurred 1 or more days before the start of the inter-luteal interval; and (c) IOI was retained if gap occurred 1 or more days before start of the next luteal cycle.

The classical fertility traits interval from calving to first service (CFS) and calving interval (CInt) were also analyzed in the GWAS. The trait CInt was restricted between 300 and $700 \mathrm{~d}$, whereas CFS was restricted to 30 and $250 \mathrm{~d}$.

\section{Genotypes and Imputation}

Genotyping of cows from the experimental herds was performed with the Illumina BovineSNP50 v1 BeadChip (Illumina Inc., San Diego, CA) on 1,946 cows and contained 54,001 SNP (50k), whereas 1,907 cows on commercial herds were genotyped with the GeneSeek Genomic Profiler Bovine HD (GeneSeek, Lincoln, $\mathrm{NE}$ ), containing 76,883 SNP (80k). An additional 6 cows from a commercial herd were genotyped with a custom Illumina $6 \mathrm{k}$ array. The 50k and $80 \mathrm{k}$ SNP arrays had 25,815 SNP in common, and the rest were imputed from one data set to the other and vice versa using BEAGLE 3.3.2 (Browning and Browning, 2009), resulting in a total of 102,062 SNP. The quality criteria applied before imputation were minimum call rate of $95 \%$ per animal and $97 \%$ per SNP, and minimum GC score of 0.3 . A total of 120 animals failed the quality criteria and were excluded. After imputation, SNP were retained for association analysis if they fulfilled all of the following filtering criteria: call rate $>95 \%$, minor allele frequency (MAF) $>0.01$, and no extreme deviation from Hardy-Weinberg equilibrium ( $P$-value $<0.01)$. The final genotype data set contained 85,485 SNP for 3,739 cows.

\section{Statistical Analysis}

A total of 2,447 Holstein Friesian cows with 5,339 lactations with both phenotypes and genotypes were used for all association analyses. For both fine mapping and the GWAS, the association between a SNP and a phenotype was assessed by a single-locus regression for each SNP separately, using a linear mixed model that included a random polygenic effect. Because there were repeated lactations per cow, a random permanent environmental effect was also fitted. The model was as follows:

$$
\begin{aligned}
y_{i j k l m}= & \mu+\operatorname{parity}_{i}+\operatorname{hys}_{j}+b_{1} \times c a_{k}+b_{2} \times M_{l}+a_{m} \\
& +p e_{m}+e_{i j k l m},
\end{aligned}
$$

where $y_{i j k l m}$ is the phenotype; $\mu$ is the intercept, parity ${ }_{i}$ is the fixed effect of parity $i$ (cows in parity 4 or above were grouped to a common class); hys ${ }_{j}$ is the fixed effect of herd-year-(calving) season combination $j(j=$ 1-495), with calving season defined as winter: December-February, spring: March-May, summer: June-August, autumn: September-November; $b_{1} \times c a_{k}$ is the regression on calving age $k$ (in months) with coefficient $b_{1} ; M_{l}$ is the genotype score $[0,1,2$ for the GWAS with SNP-chip data, but genotype dosage (any value between 0 and 2) for the regional association study with sequence variants] of SNP $l$ for individual $m$; $b_{2}$ is the additive effect of SNP $l ; a_{m}$ is the random polygenic effect of animal $m, a_{m}$ was assumed to be normally distributed with mean zero and variance $\mathbf{A} \sigma_{a}^{2}$, where $\mathbf{A}$ is the additive genetic relationship matrix; $p e_{m}$ is the random permanent environmental effect of animal $m$ to account for repeated measures (i.e., more than one lactation) within animal, $p e_{m}$ was assumed to be normally distributed with mean zero and variance $\sigma_{p e}^{2}$, and $e_{i j k l m}$ is the random error term, with residuals assumed to be normally distributed, with mean zero and variance $\sigma_{e}^{2}$. The variance components were re-estimated for each SNP analyzed. The F-test of the null hypothesis (no QTL, i.e., $\beta_{\mathrm{SNP}}=0$ ) against the alternative (a QTL is present, i.e., $\beta_{\mathrm{SNP}} \neq 0$ ) was performed for each SNP.

Heritability and repeatability estimates were calculated from univariate analyses using the same model, but with the SNP effect excluded. Because LA60 is a binary trait, it was analyzed with a threshold model, which included the same fixed and random effects as described above. All statistical analyses were performed in ASReml 4.1 (Gilmour et al., 2014).

\section{Imputation to Sequence}

The multi-breed sequenced population from the 1,000 Bulls Genomes Project Run 4 was used as reference population for imputation to sequence and contained 1,147 sequenced animals with on average 11-fold coverage. The reference population contained 311 Holstein bulls, but all individuals were used as reference because earlier studies have shown that a multi-breed sequenced reference population can be beneficial for imputation accuracy, especially for variants with low minor allele frequency (Bouwman and Veerkamp, 2014; Daetwyler et al., 2014). Imputation was done using MINIMAC2 
Table 1. Target regions from sequence data selected based on a genome-wide association study with 85,485 SNP in Bos taurus

\begin{tabular}{|c|c|c|c|c|c|c|}
\hline BTA & $\begin{array}{c}\text { Target } \\
\text { region }(\mathrm{Mb})\end{array}$ & $\begin{array}{l}\text { Position top } \\
\text { SNP (bp) }\end{array}$ & $\begin{array}{c}\text { No. of } \\
\text { significant SNP }\end{array}$ & $\begin{array}{l}\text { No. of SNP } \\
\text { on } 85 \mathrm{k}\end{array}$ & $\begin{array}{l}\text { No. of variants } \\
\text { on sequence }\end{array}$ & $\begin{array}{l}\text { Traits }^{1} \text { showing } \\
\text { association }\end{array}$ \\
\hline$\overline{2}$ & $1.87-15.30$ & $6,852,950$ & 8 & 202 & 161,426 & C-LA, CLAFS, LPL \\
\hline 2 & $31.87-41.96$ & $36,891,323$ & 3 & 320 & 97,548 & LPL, IOI \\
\hline
\end{tabular}

${ }^{1} \mathrm{C}-\mathrm{LA}=$ commencement of luteal activity, PLA $=$ proportion of samples in luteal activity between 25 and 60 DIM, LA60 = luteal activity between 25 and 60 DIM, CLAFS = interval from commencement of luteal activity to first service, LPL $=$ first luteal phase length, IOI $=$ length of first inter-ovulatory interval.

(Fuchsberger et al., 2015) with pre-phased genotypes from BEAGLE. As described by Daetwyler et al. (2014), the genotype calls of 1,000 Bull Genomes reference population were improved with BEAGLE using genotype likelihoods from SAMtools (Li et al., 2009) and inferred haplotypes in the samples, the resulting phased genotypes were used directly as pre-phased reference genotypes in MINIMAC2. Also the target population had pre-phased genotypes due to the imputation step in BEAGLE described above.

Defining QTL Regions. The QTL regions from the GWAS were defined based on the location of the significant SNP. A chromosomal region was defined as a QTL when at least 2 SNP within a $10-\mathrm{Mb}$ region showed genome-wide significant association with a trait. Single, isolated, significant SNP were excluded from QTL definition because they have a high risk of representing a false positive.

Significant Associations. In association analyses with a dense marker map, results are obscured by issues related to multiple testing and high correlations between close markers due to LD. As suggested by Teyssèdre et al. (2012), $3 P$-value thresholds were used to identify and describe regions of interest. The most stringent threshold of $10^{-6}$ was chosen as an approximation of the tests corrected with Bonferroni. The threshold of $10^{-5}$ was used to provide moderate evidence of association (Wellcome Trust Case Control Consortium, 2007). A less stringent threshold of $10^{-4}$ was used to detect associations from the GWAS scan, and to describe and compare QTL between traits.

Selecting Target Regions. Three chromosomal regions were targeted for fine mapping based on results of the GWAS with 85,485 SNP for the endocrine fertility traits. The target regions were selected based on association signals across multiple traits. The full chromosomes containing these regions were then imputed to sequence level, and the regions for fine-mapping extracted. There were 2 target regions on BTA 2, and one target region on BTA 3. The number of imputed sequence variants in the target regions ranged from 89,632 to 161,426 . The lengths of the target regions and number of imputed variants (SNP and short inser- tions and deletions) based on whole-genome sequence are listed in Table 1. Filtering out imputed variants, with MAF <0.01, resulted in 109,051 and 57,622 variants for the target regions of BTA $2(1.87-15.30 \mathrm{Mb}$ and 31.87-41.96 Mb, respectively), and 58,894 variants on BTA 3 (85.68-95.66 Mb). Region-wise association analysis with the sequence variants was performed with the same model used in the GWAS.

Candidate Genes. Based on the region-wise association results for each target region, putative candidate genes were searched for in the regions flanking the most significant variant. We kept the genes closest to the most significant variant. The candidate genes were identified based on the Bos taurus UMD3.1 genome assembly (Zimin et al., 2009), and visualized using locusZoom (Pruim et al., 2010). The gene information was extracted from the Ensembl database http://www. ensembl.org (Cunningham et al., 2015): Ensembl Bos taurus 81.31, UMD3.1.

\section{RESULTS}

For all the fertility traits analyzed, descriptive statistics, heritability, and repeatability estimates are in Table 2. Heritability estimates ranged from 0.03 to 0.15 , whereas repeatability estimates ranged from 0.14 to 0.34 . The trait ILI had zero heritability, hence was excluded from further analysis.

\section{Genome-Wide Association Study}

The average inflation factor of $P$-values from the GWAS was $1.08 \pm 0.061$, with a minimum of 0.99 for IOI, and a maximum of 1.16, for PLA, indicating relatively good concordance between observed and assumed distributions of the test statistics. The quantilequantile plots of all the GWAS are in Supplemental Figure S1 (http://dx.doi.org/10.3168/jds.2015-10533).

The Manhattan plots for all fertility traits analyzed with the 85,485 SNP are in Figure 1, and Figure 2 shows the location of all SNP-trait associations on the 30 chromosomes. In total, 150 SNP-trait associations $\left[-\log _{10}(P\right.$-value $\left.)>4\right]$ were detected across all chromo- 
somes except on BTA 4, 22, 26, and 28. For endocrine fertility traits, 123 SNP-trait associations were found on all chromosomes except on BTA 4, 22, 26, and 28. The greatest number of associated SNP were on BTA 2, followed by BTA 3 and BTA 17. All associated SNP from the GWAS are in Supplemental Table S1 (http:// dx.doi.org/10.3168/jds.2015-10533).

A total of 20 QTL regions (of which 17 were for endocrine traits) were identified for all the fertility traits except CInt, on 8 chromosomes (BTA 2, 3, 8, 12, 15, 17, 23, and 25; Table 3). The trait PLA had the highest number of QTL regions (5), followed by CLAFS (4). The traits LA60, LPL, and CFS each had 3 QTL regions, whereas C-LA and IOI had a QTL region each. As shown in Table 4, the top associated SNP in a QTL for C-LA and PLA were observed on BTA 3 at 90.67 $\mathrm{Mb}$, and 95.24 Mb for LA60. The top QTL for CLAFS was on BTA $2(74.44 \mathrm{Mb})$, whereas that of LPL and IOI was on BTA 2 at $36.89 \mathrm{Mb}$. The magnitude of estimated SNP effects (Table 4) was expressed in trait phenotypic standard deviation units. The absolute SNP effects ranged from 0.12 for CFS to 0.93 for LA60.

Two QTL regions were shared by multiple endocrine fertility traits on BTA 2 and 3 (Table 3). The QTL region on BTA $2(36.88-37.05 \mathrm{Mb})$ was shared by LPL and IOI. The top associated SNP in this region was for LPL $\left[-\log _{10}(P\right.$-value $\left.)=4.96\right]$, with a total of $3 \mathrm{SNP}$ associations for both LPL and IOI; also, the other 2 associated SNP had the same $P$-value as the top associated SNP, suggesting strong LD. The region on BTA 3 (90.67-95.24 Mb) was shared by C-LA, PLA, and LA60, with the topmost association being for PLA $\left[-\log _{10}(P\right.$-value $\left.)=6.41\right]$, followed by LA60 and C-LA (Table 4).

Twenty-nine SNP-trait associations $\left[-\log _{10}(P\right.$-value $)$ $>4$ ] were identified for classical fertility traits (CFS and CInt) across 18 chromosomes (Figure 2). The most significant SNP association for CInt $\left[-\log _{10}(P\right.$-value $)$ $=5.78]$ was on BTA $11(76.42 \mathrm{Mb})$. A total of $3 \mathrm{QTL}$ regions were identified for CFS (on BTA 3, 15, and 23), and none for CInt (Table 3). The top QTL region for CFS ranged from 27.78 to $30.35 \mathrm{Mb}$ on BTA 23 [$\log _{10}(P$-value $\left.)=6.35\right]$, which was also associated with CLAFS $\left[-\log _{10}(P\right.$-value $\left.)=4.50\right]$.

\section{Fine-Mapping with Sequence Variants}

Three target regions on BTA 2 and 3 were finemapped for 6 endocrine fertility traits by region-wise association analysis using imputed sequence variants (Table 1$)$. A total of 4,747 associations $\left[-\log _{10}(P\right.$-value $)$ $>4]$ between sequence variants and 6 endocrine fertility traits were identified on all target regions. All variants associated with the analyzed endocrine fertility traits are in Supplementary Table S2 (http://dx.doi. org/10.3168/jds.2015-10533), and the most significantly associated variants in each region are in Table 5 . The most likely candidate genes for each target region, based on proximity to the most significant variant, are in Table 6.

The target region on BTA $2(1.87-15.30 \mathrm{Mb})$ was fine-mapped for C-LA, CLAFS, and LPL, and varianttrait associations were observed for all traits. In total, 45 associations were identified for C-LA, 716 for CLAFS and 564 for LPL. The most significant association was observed for CLAFS $\left[-\log _{10}(P\right.$-value $\left.)=6.89\right]$ at 7.18 $\mathrm{Mb}$ (Table 5$)$, followed by LPL $\left[-\log _{10}(P\right.$-value $\left.)=6.62\right]$ at $8.45 \mathrm{Mb}$, and C-LA $\left[-\log _{10}(P\right.$-value $\left.)=4.75\right]$ at 14.02 $\mathrm{Mb}$. Based on the region-wise association results, candidate genes were searched for in the region spanning $12,499,856$ to $15,303,929 \mathrm{bp}$ for C-LA, and $3,499,960$ to 10,999,836 bp for CLAFS and LPL (Figure 3). A total of 83 genes were identified for CLAFS and LPL, of which 61 are annotated and 22 uncharacterized. There were 24 genes for C-LA, with 16 annotated. The annotated genes closest to the most significant variant were $P D E 1 A$ for C-LA, SLC40A1 for CLAFS, and GULP1 for LPL (Table 6).

Table 2. Number of lactations (n) per trait, overall mean, SD, estimates of heritability $\left(\mathrm{h}^{2}\right)$, repeatability (t), and their SE for various endocrine and classical fertility traits

\begin{tabular}{lcrrrrr}
\hline Trait $^{1}$ & $\mathrm{n}$ & Mean & $\mathrm{SD}$ & $\mathrm{h}^{2}$ & $\mathrm{SE}$ & $\mathrm{t}$ \\
\hline C-LA (d) & 3,524 & 38.53 & 18.04 & 0.14 & 0.04 & 0.34 \\
PLA (\%) & 3,597 & 0.56 & 0.30 & 0.15 & 0.04 & 0.32 \\
LA60 (0-1) & 3,597 & 0.87 & 0.33 & 0.15 & 0.06 & 0.19 \\
CLAFS (d) & 2,015 & 51.23 & 30.83 & 0.09 & 0.05 & 0.29 \\
LPL (d) & 1,785 & 12.54 & 11.09 & 0.15 & 0.05 & 0.15 \\
IOI (d) & 1,658 & 26.71 & 14.91 & 0.14 & 0.05 & 0.03 \\
ILI (d) & 1,637 & 10.95 & 11.04 & 0.00 & 0.00 & 0.05 \\
CFS (d) & 3,631 & 90.85 & 33.72 & 0.10 & 0.04 & 0.00 \\
CInt (d) & 2,031 & 408.46 & 65.17 & 0.03 & 0.04 & 0.15 \\
\hline
\end{tabular}

${ }^{1} \mathrm{C}-\mathrm{LA}=$ commencement of luteal activity; PLA $=$ proportion of samples in luteal activity between 25 and 60 DIM; LA60 = luteal activity between 25 and 60 DIM, CLAFS = interval from commencement of luteal activity to first service; LPL = first luteal phase length; IOI = length of first inter-ovulatory interval; ILI = inter-luteal interval; CFS = interval from calving to first service; CInt = calving interval. 
Two traits (LPL and IOI) were fine-mapped for the second target region on BTA 2 (31.87-41.96 Mb). There were 477 variants associated with LPL and 70 with IOI. The most significant association for LPL [$\log _{10}(P$-value $\left.)=9.09\right]$ was at $39.45 \mathrm{Mb}$, and at 39.48
$\mathrm{Mb}$ for IOI $\left[-\log _{10}(P\right.$-value $\left.)=6.03\right]$. The region between 33,500,042 and 40,999,921 bp was searched for candidate genes, and resulted in 62 genes, of which 45 were annotated and 17 were uncharacterized. The annotated gene closest to the most significant variant for
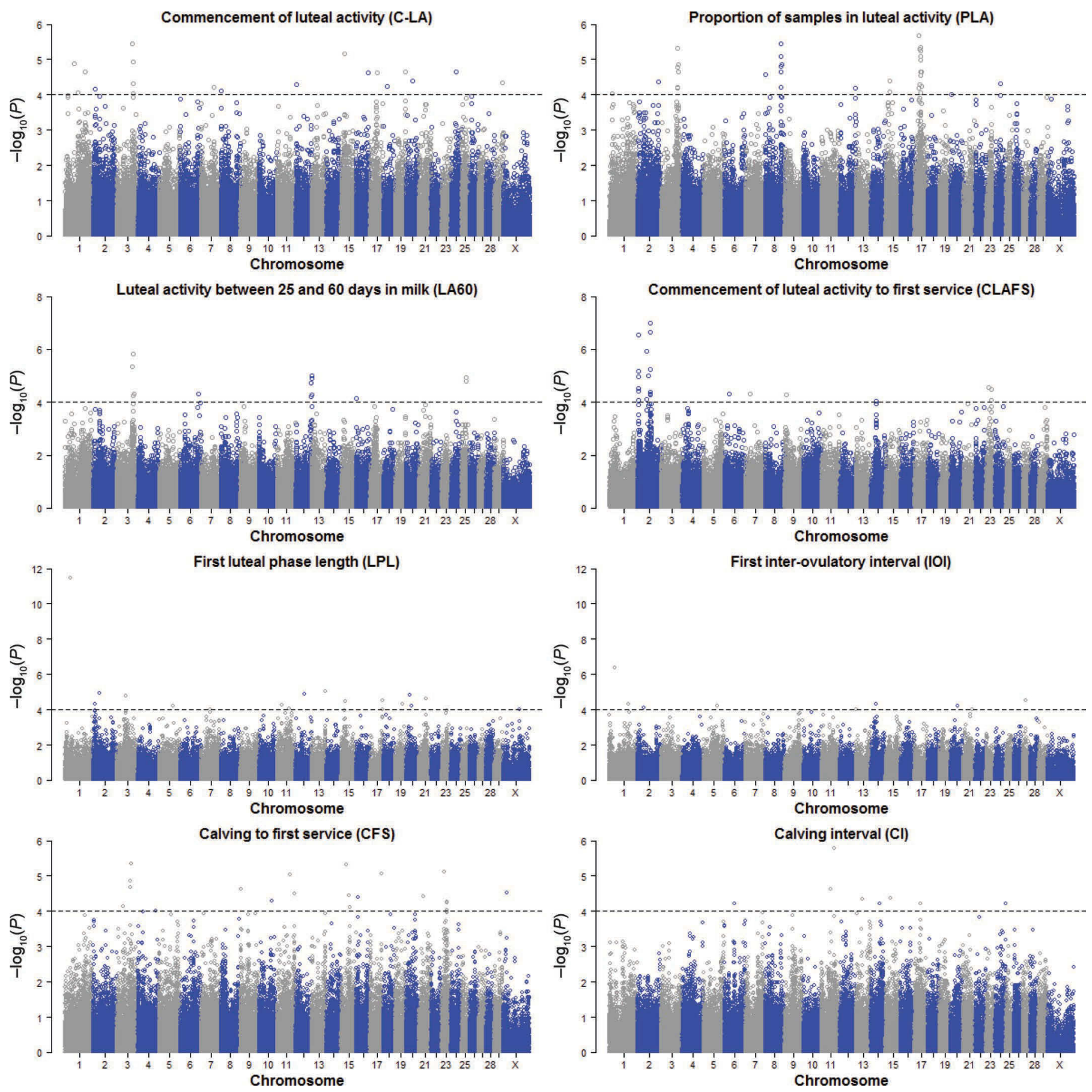

Figure 1. Genome-wide scan for 6 endocrine and 2 classical fertility traits using 85,485 SNP of 2,447 cows with 5,339 lactations in dairy cattle. The y-axis shows the $-\log _{10}(P$-value) for each SNP. The $\mathrm{x}$-axis shows the chromosomes and SNP position; chromosomes are shown in alternating colors for clarity. The dotted line represents the significance threshold $\left[-\log _{10}(P\right.$-value $\left.)=4\right]$ as considered in the present study, Color version available online. 
Table 3. The $\mathrm{QTL}^{1}$ regions on chromosomes of Bos taurus (BTA) associated with endocrine and classical fertility traits

\begin{tabular}{llccc}
\hline BTA & Trait $^{2}$ & No. $^{3}$ & Start QTL (bp) & End QTL (bp) \\
\hline 2 & CLAFS & 5 & $6,852,950$ & $7,561,006$ \\
2 & LPL & 3 & $36,777,703$ & $37,051,246$ \\
2 & IOI & 3 & $36,777,703$ & $37,051,246$ \\
2 & CLAFS & 2 & $53,979,862$ & $55,566,541$ \\
2 & CLAFS & 6 & $71,779,928$ & $74,548,518$ \\
3 & LPL & 2 & $50,948,690$ & $51,069,220$ \\
3 & CFS & 3 & $79,997,340$ & $80,486,264$ \\
3 & C-LA & 4 & $90,669,666$ & $95,240,284$ \\
3 & PLA & 7 & $90,669,666$ & $96,563,383$ \\
3 & LA60 & 4 & $90,669,666$ & $97,118,294$ \\
8 & PLA & 6 & $91,395,466$ & $90,422,712$ \\
12 & LA60 & 5 & $86,501,602$ & $24,257,848$ \\
15 & PLA & 2 & $24,225,492$ & $51,499,475$ \\
15 & CFS & 2 & $43,813,899$ & $34,816,827$ \\
17 & PLA & 8 & $25,146,353$ & $40,308,609$ \\
17 & PLA & 5 & $35,229,850$ & $72,151,374$ \\
17 & LPL & 2 & $70,962,192$ & $30,349,749$ \\
23 & CFS & 5 & $27,776,075$ & $29,385,602$ \\
23 & CLAFS & 2 & $28,855,836$ & $23,372,664$ \\
25 & LA60 & 2 & $23,315,423$ & \\
\hline
\end{tabular}

${ }^{1}$ QTL region defined as a chromosomal region with multiple significant SNP within a window of $10 \mathrm{Mb}$.

${ }^{2} \mathrm{C}-\mathrm{LA}=$ commencement of luteal activity; PLA = proportion of samples in luteal activity between 25 and 60 DIM; LA60 = luteal activity between 25 and 60 DIM, CLAFS = interval from commencement of luteal activity to first service; $\mathrm{LPL}=$ first luteal phase length; $\mathrm{IOI}=$ length of first inter-ovulatory interval; $\mathrm{CFS}=$ interval from calving to first service.

${ }^{3}$ No. $=$ number of significant SNP within the QTL.

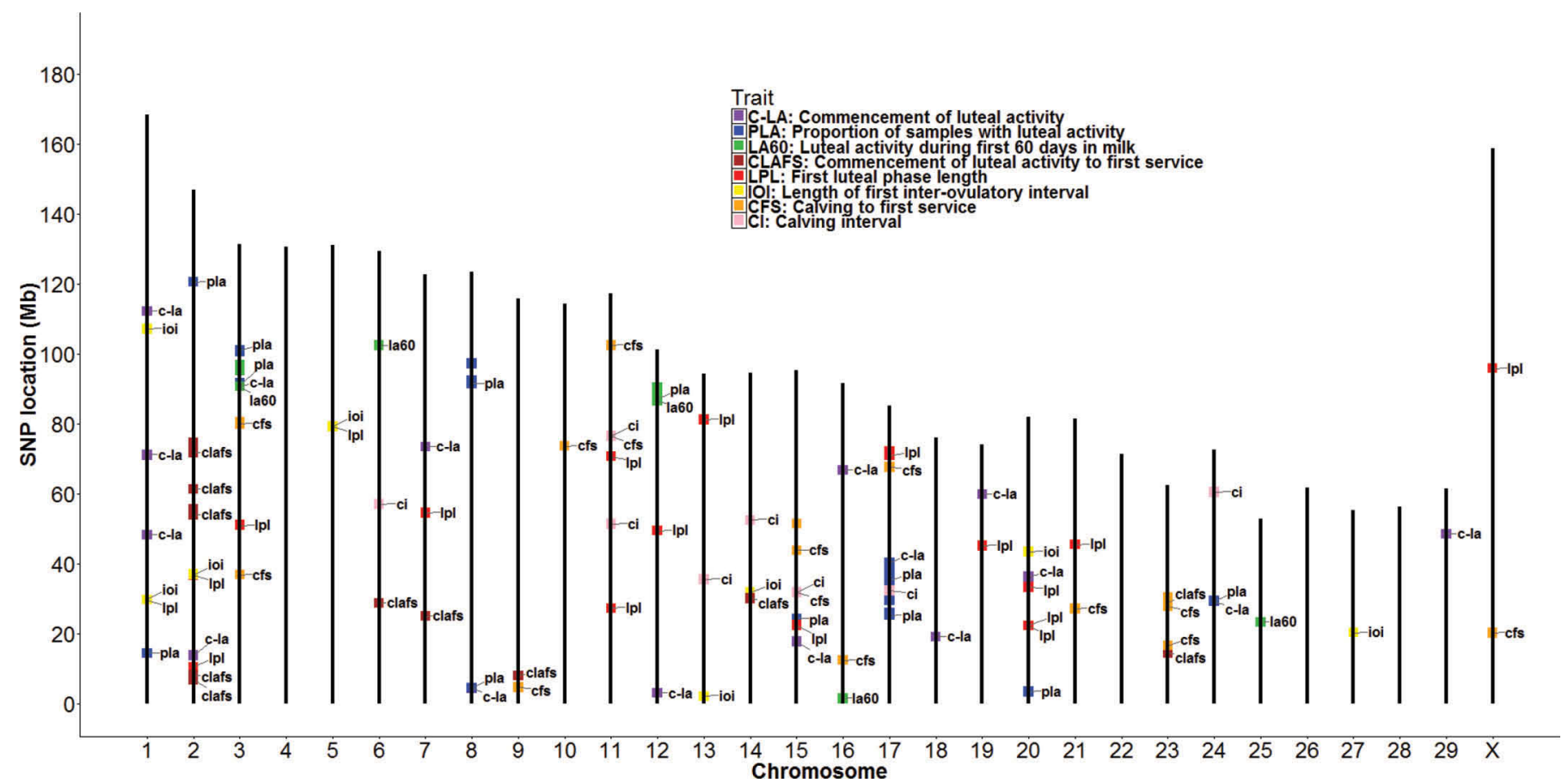

Figure 2. Distribution along the chromosomes of SNP with $P$-value $<10^{-4}$, identified for 6 endocrine and 2 classical fertility traits in dairy cattle, from a genome-wide scan using 85,485 SNP of 2,447 cows with 5,339 lactations. Color version available online. 
Table 4. The most significantly associated SNP in QTL ${ }^{1}$ regions identified on chromosomes of Bos taurus from a genome-wide association study of fertility traits with 85,485 SNP

\begin{tabular}{|c|c|c|c|c|c|c|}
\hline BTA & Trait $^{2}$ & $\begin{array}{l}\text { Position } \\
\text { top SNP }\end{array}$ & $\mathrm{MAF}^{3}$ & $-\log (P$-value $)$ & $\begin{array}{l}\text { Effect } \\
\text { in } \mathrm{SD}^{4}\end{array}$ & $\begin{array}{c}\mathrm{SE} \text { in } \\
\mathrm{SD}^{4}\end{array}$ \\
\hline 2 & CLAFS & $6,852,950$ & 0.33 & 6.53 & -0.19 & 0.04 \\
\hline 2 & LPL & $36,777,703$ & 0.06 & 4.96 & 0.33 & 0.07 \\
\hline 2 & IOI & $36,777,703$ & 0.06 & 4.09 & 0.29 & 0.07 \\
\hline 2 & CLAFS & $55,566,541$ & 0.03 & 5.91 & -0.45 & 0.09 \\
\hline 2 & CLAFS & $74,444,101$ & 0.45 & 7.01 & -0.18 & 0.03 \\
\hline 3 & LPL & $51,069,220$ & 0.31 & 4.78 & -0.18 & 0.04 \\
\hline 3 & CFS & $80,486,264$ & 0.4 & 5.34 & -0.12 & 0.03 \\
\hline 3 & C-LA & $90,669,666$ & 0.2 & 5.46 & 0.16 & 0.04 \\
\hline 3 & PLA & $90,669,666$ & 0.2 & 6.41 & -0.17 & 0.03 \\
\hline 3 & LA60 & $95,240,284$ & 0.22 & 5.83 & -0.86 & 0.10 \\
\hline 8 & PLA & $91,401,417$ & 0.11 & 5.45 & 0.21 & 0.05 \\
\hline 12 & LA60 & $90,422,712$ & 0.26 & 5.00 & 0.85 & 0.11 \\
\hline 15 & PLA & $24,257,848$ & 0.21 & 4.40 & -0.14 & 0.03 \\
\hline 15 & CFS & $43,813,899$ & 0.03 & 4.45 & 0.32 & 0.08 \\
\hline 17 & PLA & $25,146,353$ & 0.32 & 5.68 & -0.14 & 0.03 \\
\hline 17 & PLA & $36,525,393$ & 0.16 & 5.10 & 0.17 & 0.04 \\
\hline 17 & LPL & $70,962,192$ & 0.07 & 4.52 & 0.30 & 0.07 \\
\hline 23 & CLAFS & $28,855,836$ & 0.49 & 4.50 & -0.14 & 0.03 \\
\hline 23 & CFS & $28,855,836$ & 0.49 & 6.35 & -0.13 & 0.03 \\
\hline 25 & LA60 & $23,315,423$ & 0.12 & 4.94 & -0.93 & 0.12 \\
\hline
\end{tabular}

${ }^{1}$ QTL region defined as a chromosomal region with multiple significant SNP within a window of $10 \mathrm{Mb}$.

${ }^{2} \mathrm{C}-\mathrm{LA}=$ commencement of luteal activity; PLA = proportion of samples in luteal activity between 25 and 60 DIM; LA60 = luteal activity between 25 and 60 DIM; CLAFS $=$ interval from commencement of luteal activity to first service; LPL = first luteal phase length; IOI = length of first inter-ovulatory interval; CFS $=$ interval from calving to first service.

${ }^{3} \mathrm{MAF}=$ minor allele frequency.

${ }^{4} \mathrm{SD}=$ allele substitution effect expressed in phenotypic SD of trait.

both LPL and IOI was NR4A2 (Figure 4), and another interesting candidate gene was $A C V R 1$.

The target region on BTA $3(85.68-95.66 \mathrm{Mb})$ was fine-mapped for C-LA, PLA, and LA60, and varianttrait associations were observed for all 3 traits. There were 594 variants associated with C-LA, 1,298 with PLA, and 983 with LA60. The most significant association was observed for PLA $\left[-\log _{10}(P\right.$-value $\left.)=7.84\right]$ at 89.4 Mb (Table 5); this SNP was also the most signifi- cant for LA60 $\left[-\log _{10}(P\right.$-value $\left.)=7.11\right]$. For C-LA, the most significant association $\left[-\log _{10}(P\right.$-value $\left.)=6.10\right]$ was at $89.8 \mathrm{Mb}$. Candidate genes were searched for in the region spanning $87,500,158$ to $95,662,104 \mathrm{bp}$. There were 105 genes in this region, of which 76 have been annotated, and 26 were described as uncharacterized. The annotated genes closest to the most significant variant were $D A B 1$ for C-LA and $C 8 B$ for PLA and LA60 (Figure 5).

Table 5. The most significantly associated variants from region-wise association analysis of 6 endocrine fertility traits in target regions of Bos taurus chromosomes using imputed sequence variants

\begin{tabular}{lllrrrrrr}
\hline BTA & Trait & Top variant & Position & $-\log _{10}(P$-value $)$ & MAF & $\begin{array}{c}\text { Effect } \\
\text { in SD }\end{array}$ & $\begin{array}{c}\text { SE } \\
\text { in SD }\end{array}$ & rs-ID $^{3}$ \\
\hline 2 & C-LA & Chr2:14019875 & $14,019,875$ & 4.75 & 0.01 & 3.68 & 0.85 & rs 472149103 \\
2 & CLAFS & Chr2:7175833 & $7,175,833$ & 6.89 & 0.08 & 1.38 & 0.26 & rs479466942 \\
2 & LPL & Chr2:8453071 & $8,453,071$ & 6.62 & 0.04 & -7.68 & 1.47 & rs 43288488 \\
2 & LPL & Chr2:39502686 & $39,502,686$ & 8.96 & 0.01 & -2.17 & 0.35 & rs110097322 \\
2 & IOI & Chr2:40258911 & $40,258,911$ & 5.31 & 0.01 & -1.91 & 0.42 & rs378841057 \\
3 & C-LA & Chr3:89795380 & $89,795,380$ & 6.10 & 0.18 & -0.22 & 0.04 & rs451081085 \\
3 & PLA & Chr3:89360154 & $89,360,154$ & 7.84 & 0.08 & 0.88 & 0.15 & rs461884243 \\
3 & LA60 & Chr3:89360154 & $89,360,154$ & 7.11 & 0.08 & 4.45 & 0.45 & rs461884243 \\
\hline
\end{tabular}

${ }^{1} \mathrm{C}-\mathrm{LA}=$ commencement of luteal activity; PLA $=$ proportion of samples in luteal activity between 25 and 60 DIM; LA60 = luteal activity between 25 and 60 DIM; CLAFS = interval from commencement of luteal activity to first service; LPL $=$ first luteal phase length; IOI $=$ length of first inter-ovulatory interval.

${ }^{2} \mathrm{MAF}=$ minor allele frequency.

${ }^{3} \mathrm{SD}=$ allele substitution effect expressed in phenotypic SD of trait.

${ }^{4} \mathrm{rs}-\mathrm{ID}=$ reference SNP identification. 

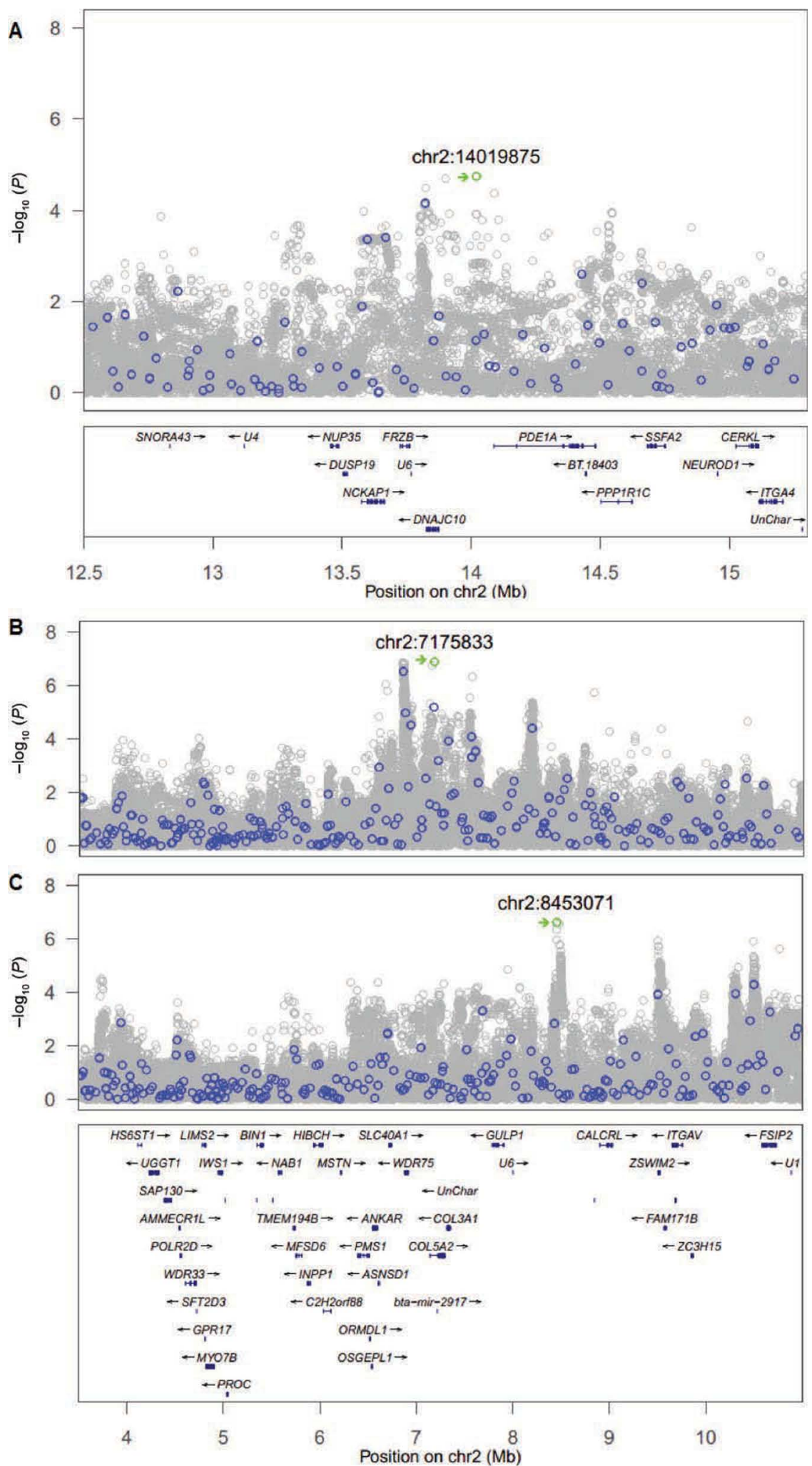

Figure 3. Region-wise association using sequence variants within the target region on BTA 2 from 12,499,856 to 15,303,929 bp for (A) C-LA, and 3,499,960 to 10,999,836 bp for (B) interval from commencement of luteal activity to first service (CLAFS) and (C) first luteal phase length (LPL). Black (blue) circles = genome-wide association with 85,485 SNP of 2,447 cows; gray circles = region-wise association analysis with imputed sequence variants; labeled circle with arrow (green circle) is the most significant variant in the region. Candidate genes in the target regions are annotated in the boxes below each target region. Color version available online. 

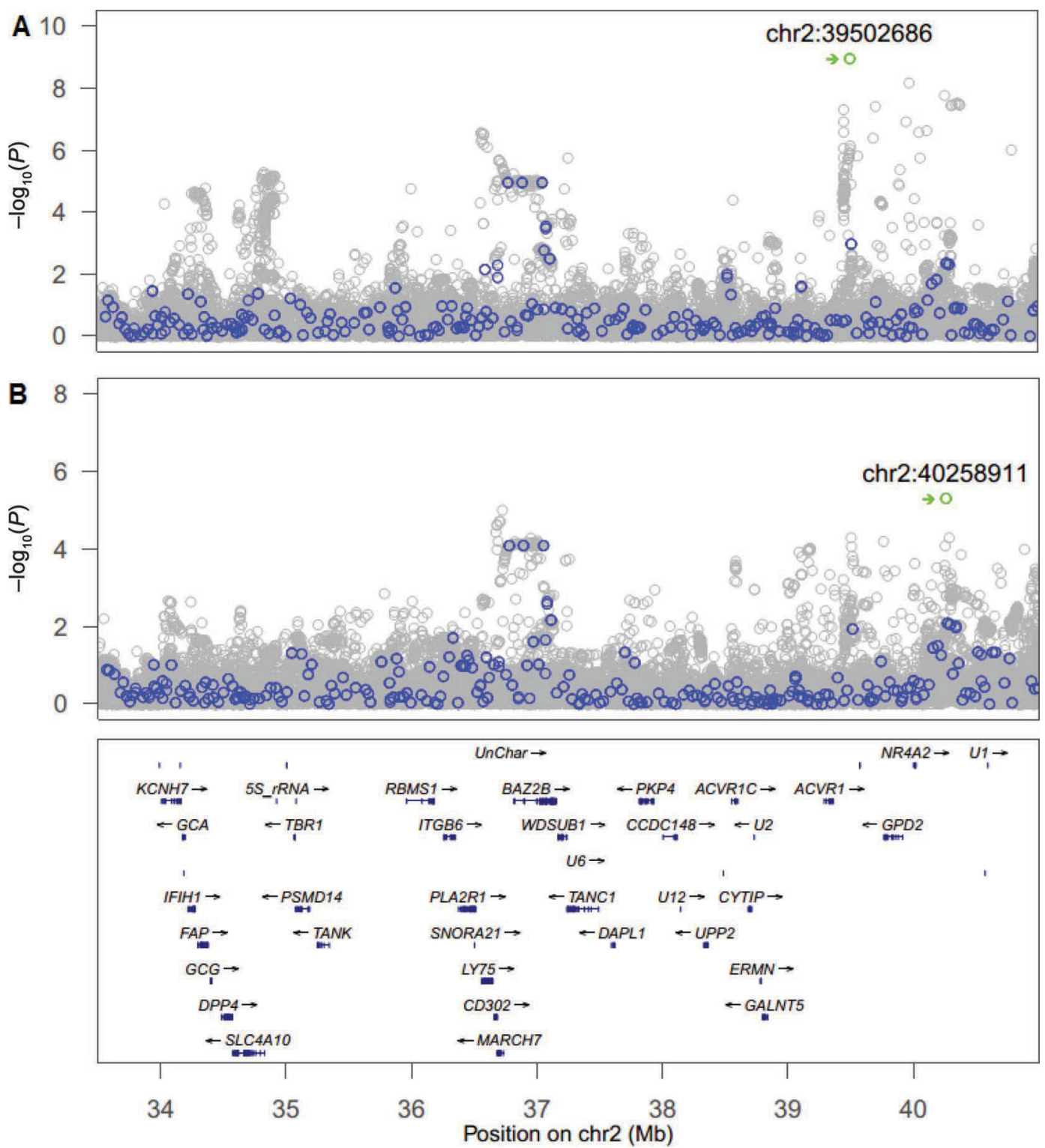

Figure 4. Region-wise association using sequence variants within the target region on BTA 2 from 33,500,042 to 40,999,921 bp for (A) first luteal phase length (LPL) and (B) length of first inter-ovulatory interval (IOI). Black (blue) circles = genome-wide association with 85,485 SNP of 2,447 cows; gray circles = region-wise association analysis with imputed sequence variants; labeled circle with arrow (green circle) is the most significant variant in the region. Candidate genes are annotated below the target region. Color version available online.

Table 6. The most likely candidate genes (top candidate) for 6 endocrine fertility traits on target regions of Bos taurus chromosomes

\begin{tabular}{lllcll}
\hline BTA & Trait $^{1}$ & $\begin{array}{l}\text { Top } \\
\text { candidate }\end{array}$ & $\begin{array}{c}\text { Start gene } \\
(\mathrm{Mb})\end{array}$ & $\begin{array}{c}\text { End gene } \\
(\mathrm{Mb})\end{array}$ & Gene description \\
\hline 2 & C-LA & PDE1A & 14.09 & 14.48 & Phosphodiesterase 1A, calmodulin-dependent \\
2 & CLAFS & SLC40A1 & 6.72 & 6.74 & Solute carrier family 40 (iron-regulated transporter) \\
2 & LPL & GULP1 & 7.83 & 8.07 & GULP, engulfment adaptor PTB domain containing 1 \\
2 & LPL, IOI & NR4A2 & 40.00 & 40.02 & Nuclear receptor subfamily 4, group A, member 2 \\
2 & LPL, IOI & ACVR1 & 39.26 & 39.36 & Activin A receptor, type I \\
3 & C-LA & DAB1 & 88.37 & 89.72 & Dab, reelin signal transducer, homolog 1 (Drosophila) \\
3 & PLA, LA60 & C8B & 89.74 & 89.79 & Complement component 8, $\beta$ polypeptide \\
\hline
\end{tabular}

${ }^{1}$ C-LA $=$ commencement of luteal activity; PLA $=$ proportion of samples in luteal activity between 25 and 60 DIM; LA60 = luteal activity between 25 and 60 DIM; CLAFS = interval from commencement of luteal activity to first service; LPL $=$ first luteal phase length; IOI $=$ length of first inter-ovulatory interval. 

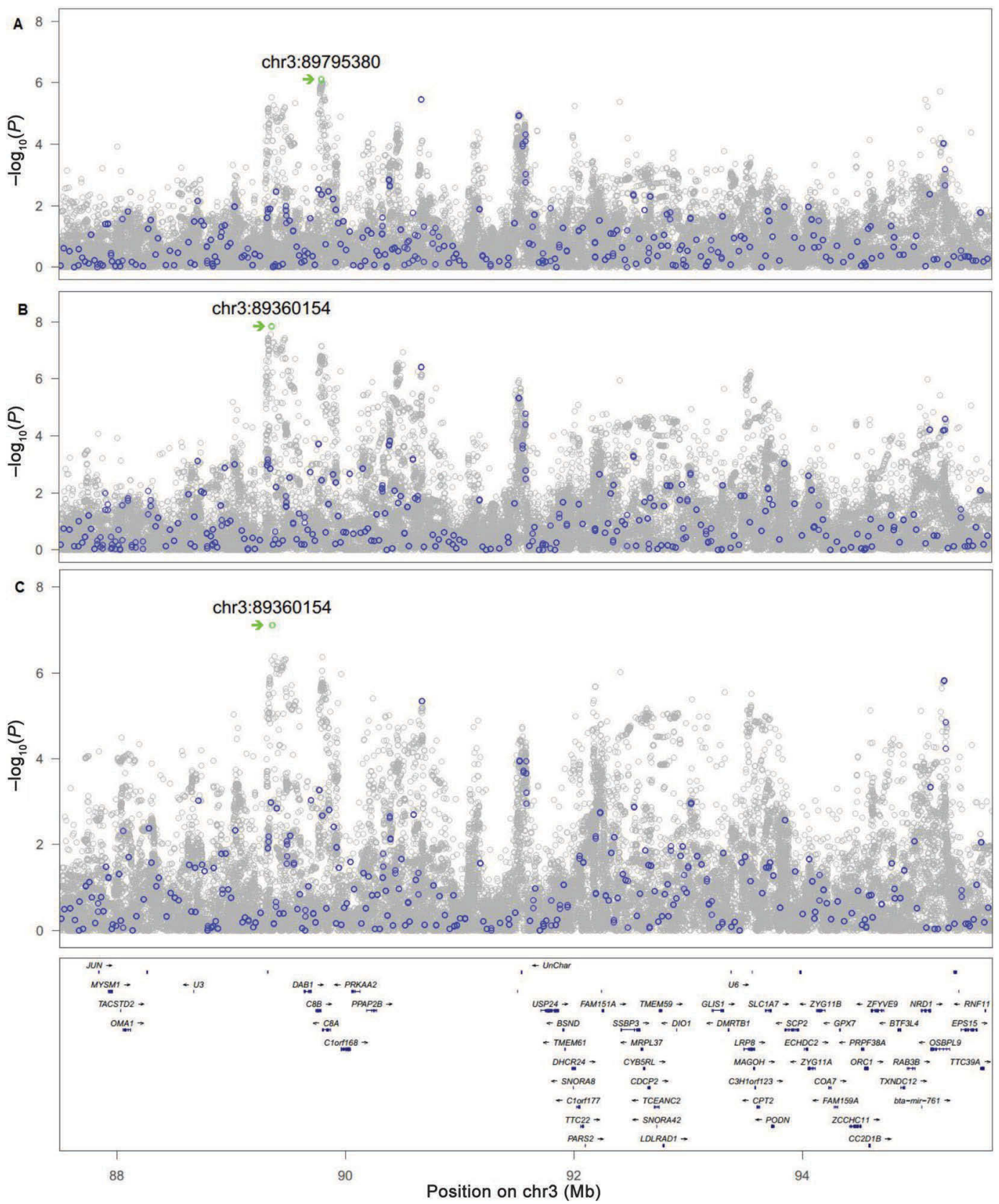

Figure 5. Region-wise association using sequence variants within the target region on BTA 3 from 87,500,158 to $95,662,104$ bp for (A) commencement of luteal activity (C-LA), (B) proportion of samples in luteal activity between 25 and 60 DIM (PLA), and (C) luteal activity between 25 and 60 DIM (LA60). Black (blue) circles = genome-wide association with 85,485 SNP of 2,447 cows; gray circles = region-wise association analysis with imputed sequence variants; labeled circle with arrow (green circle) is the most significant variant in the region. Candidate genes are annotated below the target region. Color version available online.

\section{DISCUSSION}

Previous studies have shown that endocrine fertility traits derived from milk progesterone profiles have higher heritability than classical fertility traits (Veerkamp et al., 2000; Petersson et al., 2007; Tenghe et al., 2015). Heritability estimates of the endocrine fertility traits in this study were similar to estimates reported by Veerkamp et al. (2000), and Nyman et al. (2014) who used a subset of the data used in this study, and estimates for classical fertility traits were similar to those of previous studies (Campos et al., 1994; Pryce et al., 1998; Berry et al., 2003; VanRaden et al., 2004). The trait ILI had zero heritability. Tenghe et al. (2015) 
also reported a heritability of zero for ILI, although Nyman et al. (2014) reported a heritability of 0.08 .

\section{Genome-Wide Association Study}

Detecting QTL for fertility traits is of high importance due to the low heritability of these traits. In this study, a GWAS was performed for 6 endocrine and 2 classical fertility traits using $85 \mathrm{k}$ SNP. The GWAS identified 20 QTL regions for all the fertility traits except CInt on BTA 2, 3, 8, 12, 15, 17, 23, and 25. Three selected target QTL regions on BTA 2 and 3, were then fine-mapped for endocrine fertility traits using imputed sequence variants. The endocrine trait PLA had the highest number (5) of QTL regions from the GWAS. The top QTL for PLA on BTA 3 (90.67 $\mathrm{Mb}$ ) was also associated with C-LA, and with LA60 (at 95.24 Mb), an observation consistent with the genetic correlation between these traits. Tenghe et al. (2015) reported strong genetic correlations of -0.91 for C-LA with PLA and 0.82 for PLA with LA60. Up till now, no QTL have been reported for C-LA in this region. Using a subset $(1,570$ cows from the experimental herds; $50 \mathrm{k}$ SNP) of the data used in this study, Berry et al. (2012) identified QTL for C-LA at 130,141,723 bp on BTA 2 and 9,375,095 bp on BTA 21. No QTL was identified for C-LA on BTA 21 in this study; however, a single SNP association was observed at $13,821,980 \mathrm{bp}$ on BTA 2, which is $116.32 \mathrm{Mb}$ away from the QTL observed by Berry et al. (2012). Discrepancies between sample size, methods of analysis, and marker density could explain the differences between the results of Berry et al. (2012) and our study.

To the best of our knowledge, with the exception of C-LA, no QTL have been reported for the other endocrine fertility traits analyzed in this study. In this study, the top QTL for LPL on BTA 2 was also associated with IOI. As expected from the trait definition, IOI combines information from LPL and ILI, hence it is likely that IOI and LPL are influenced by overlapping groups of genes.

The top QTL for CFS on BTA $23(28.86 \mathrm{Mb})$ was also associated with CLAFS. The shared QTL region by CFS and CLAFS could be expected, given the trait definition. The trait CLAFS is not entirely endocrine, but part endocrine and part classical, as it combines information from CFS and C-LA. In addition, there is a moderate genetic correlation (0.46) of C-LA and CFS, as reported by Tenghe et al. (2015). Several fertility QTL in dairy cattle have been reported on BTA 23 (Druet et al., 2008; Sahana et al., 2010; Höglund et al., 2014b). A QTL associated with veterinary treatment for reproductive disorders at $28.89 \mathrm{Mb}$ was found in Danish and Swedish Holstein (Sahana et al., 2010). A
QTL for CFS was found in Danish Holstein and validated in Danish Jersey at 28.09 Mb (Höglund et al., 2014b). They reported QTL 0.03 and $0.77 \mathrm{Mb}$ away from the QTL identified in this study, suggesting it might be the same QTL. Furthermore, using sequence variants, Höglund et al. (2015) identified a QTL region from 30 to $32 \mathrm{Mb}$ for components of a fertility index (which included CFS as component trait) in Danish Jersey; the QTL for CFS was at $30.36 \mathrm{Mb}$, which may be identical to the one we observed at $30.35 \mathrm{Mb}$ in this study.

\section{Fine-Mapping BTA 2}

The target region on BTA $2(1.87-15.30 \mathrm{Mb})$ was fine-mapped for C-LA, CLAFS, and LPL. The most likely candidate genes in this region were $P D E 1 A$ for C-LA, SLC40A1 for CLAFS, and GULP1 for LPL. The $P D E 1$ belongs to the cyclic nucleotide phosphodiesterases (PDE) that play a role in signal transduction by regulating intracellular cyclic nucleotide concentrations through hydrolysis of cyclic adenosine monophosphate (cAMP). This gene complex is known to mediate oocyte maturation by regulating cAMP concentrations (Landim-Alvarenga and Maziero, 2014). A relative increase in the level of cAMP within the oocyte is essential for maintaining meiosis block, whereas a decrease in cAMP oocyte concentration allows the resumption of meiosis (Sela-Abramovich et al., 2006; Conti et al., 2012). The protein encoded by SLC40A1 is a cell membrane protein that may be involved in iron export from duodenal epithelial cells, and defects in this gene result in hemochromatosis (Geer et al., 2010). In cattle, $S L C 40 A 1$ is suggested to be related to milk yield, but no fertility-related function is known (Fang et al., 2014). The gene GULP1 encodes an adapter protein necessary for the engulfment of apoptotic cells by phagocytes, but no fertility-related function is known for this gene.

Another target region $(31.87-41.96 \mathrm{Mb})$ on BTA 2 was fine-mapped for LPL and IOI. The most significant variant in this region was located in close proximity of NR 4A2, and ACVR1 was another interesting candidate based on its function. The gene NR4A2 is a member of the steroid receptor superfamily (Geer et al., 2010), and considered an important ovarian factor in regulation of female reproduction (Zhao et al., 2007). The $A C V R 1$ (also known as ALK2) is a dimeric growth and differentiation factor, which belongs to transforming growth factor- $\beta$ (TGF- $\beta$ ). The TGF- $\beta$ together with bone morphogenetic proteins (BMP) form a signaling family that is necessary for follicle development and oocyte competence in mammals, and different studies have demonstrated the role of specific family members 
in theca cells, granulosa cells, cumulus cells, and oocytes (Knight and Glister, 2006; Edson et al., 2009). In cattle, FSH and estradiol both play a role in regulating ACVR1 expression during follicle development, and BMP signaling through $A C V R 1$ in granulosa cells is thought to play a role in follicle growth (Shimizu et al., 2006; Glister et al., 2010). Furthermore, ACVR1 levels in granulosa cells were shown to increase with follicle size (Shimizu et al., 2006). Moreover, in equine, $A C V R 1$ is suggested to be involved with follicular fluid exosomes that regulate members of the TGFB/BMP signaling pathway in granulosa cells, and possibly play a role in regulating follicle maturation (da Silveira et al., 2014).

\section{Fine-Mapping BTA 3}

The target region on BTA $3(85.68-95.66 \mathrm{Mb})$ was fine-mapped for C-LA, PLA, and LA60. Similar to the GWAS, the most significant association $(89,360,154$ bp) was common to PLA and LA60, suggesting that indeed these traits are probably influenced by the same genes. Moreover, detecting the same QTL for genetically correlated traits improves evidence for the QTL.

In the region from $87,500,158$ to $95,662,104$ bp on BTA 3,DAB1 and $C 8 B$ were located in close proximity of the most significant variant in this region. The gene $D A B 1$ has been suggested to be involved in numerous potential physiological functions: cell adhesion processes, activation of neuron differentiation, stimulation of protein kinase activity, ventral spinal cord development, adult walking behavior, and cerebellum structural organization (Ashburner et al., 2000). In mice, the protein encoded by this gene is thought to be a signal transducer that interacts with protein kinase pathways to regulate neuronal positioning in the developing brain. The gene $C 8 B$ is involved in encoding a membrane attack complex protein that mediates cell lysis. In humans, deficiency of this protein is associated with increased risk of meningococcal infection (Geer et al., 2010). Nevertheless, none of the candidate genes in this region had obvious fertility-related functions.

\section{Limitations to Mapping Causal Mutations}

The LD in cattle is spread over a wide region due to low effective population size and strong selection. This LD breadth places limitations on mapping QTL to regions suitable for identifying causative mutations. However, using multiple-breed data may have advantage for mapping causal factors, for example, as shown in dogs (Karlsson et al., 2007). Also, studies on a more functional level may be required to be able to identify causative variants.

\section{Effect Size and Application for Breeding}

Genomic predictions are now used routinely in selection of dairy cattle (Hayes et al., 2009; Goddard et al., 2010; Wiggans et al., 2011); however, an ongoing challenge is to improve the accuracy of these predictions, as the genetic gain that can be achieved is proportional to their accuracy. Genomic prediction from whole-genome sequence data is attractive because the accuracy of genomic prediction is no longer bounded by the extent of linkage disequilibrium between DNA markers and causal mutations affecting the trait, given the causal mutations are in the data set. Although simulation studies show large gain in accuracy of genomic prediction due to use of sequence data (Meuwissen and Goddard, 2010; Clark et al., 2011; Druet et al., 2014), this has not yet been realized in real data (Ober et al., 2012; Hayes et al., 2014; van Binsbergen et al., 2015). These simulation studies also show that the added value of using sequence data over SNP arrays to increase accuracy of genomic breeding is dependent on the size and distribution of QTL effects. The absolute effect sizes of QTL detected for endocrine fertility traits in this study were low to moderate, ranging from 0.12 to 7.68 (Tables 4 and 5), suggesting that the effect of the causative mutations for endocrine fertility traits may be very small as observed for several quantitative traits (Kemper et al., 2011; Stahl et al., 2012). When QTL effects are small and MAF are low as observed for the fertility QTL in this study, large numbers of individuals are required to estimate these effects accurately, and even though the cost of genome resequencing has fallen dramatically, it is still too expensive to consider resequencing the tens of thousands of individuals that would be required to accurately estimate the likely small effects of mutations. An alternative strategy would be to sequence a relatively few individuals (key ancestors), and then impute genotypes for the variants discovered in the sequence into the whole population. Furthermore, simulation results (Druet et al., 2014) suggest that when the MAF of QTL is very low, genomic predictions from imputed sequence data can have up to $20 \%$ advantage in accuracy over use of SNP panels. In dairy cattle, such genetic architecture is most likely for a complex trait like fertility, which would benefit greatly from genomic prediction with whole-genome sequence. Another possibility to benefit from sequence data as suggested by Hayes et al., (2014) would be to preselect sequence variants based on annotation information, and include this biological information in genomic predictions. Yet another strategy could be to include the sequence variants from the causal regions on low-density chips used in genomic prediction on which a large number of individuals can be genotyped. This would increase the 
power of QTL detection; for example, a mutation in the $S M C 2$ gene that causes embryonic loss was identified using such strategy in the 1,000 bull genome project (Daetwyler et al., 2014). However, in terms of genomic prediction, these low-density chips do not provide more accuracy of prediction yet.

A sustainable breeding scheme also takes into account the correlated effects on other production and reproduction traits. In general, the genetic correlations among all the analyzed fertility traits are favorable, and therefore no serious negative effects on genetic progress due to selection are to be expected. However, the genetic correlations of milk yield with endocrine and classical fertility traits are generally unfavorable, hence special attention will be needed to optimize breeding schemes to account for these correlations. Although genetic correlation estimates of in-line endocrine fertility traits with milk yield seem lower (Tenghe et al., 2015) than genetic correlations of milk yield with classical fertility traits, more studies are needed to confirm these estimates. Hence, a plausible solution to improve fertility using endocrine fertility traits would be optimized breeding schemes that jointly include endocrine and classical fertility traits in a fertility index, with special attention given to the negative correlation of fertility with milk yield.

Nonetheless, it is not yet obvious on how to benefit directly from the endocrine traits, QTL, and sequence data, as several challenges still remain (e.g., how to translate SNP effects to economic values and optimal integration in breeding decisions) that it is not clear how to deal with. Hence, the findings in this study helped to learn more about the genetic architecture and underlying biology of fertility.

\section{CONCLUSIONS}

A total of 17 QTL regions for 6 endocrine fertility traits were identified on chromosomes $2,3,8,12,15$, 17,23 , and 25 from a genome-wide association with 85,485 SNP. Three QTL regions were identified for classical fertility traits. Overlapping QTL regions were found between endocrine traits on BTA 2, 3, and 17 and between endocrine and classical fertility traits on BTA 23. Fine-mapping of target regions for endocrine traits on BTA 2 and 3, using imputed sequence variants confirmed the QTL from the genome-wide association study, and identified several associated variants that can contribute to an index of markers for genetic improvement of fertility. Several potential candidate genes underlying endocrine fertility traits were also identified in the target regions. However, due to high LD, it was not possible to specify genes or polymorphisms as causal factors for any of the regions.

\section{ACKNOWLEDGMENTS}

The authors acknowledge Lattec I/S (Denmark) for providing the in-line progesterone data, RobustMilk project "grant agreement KBBE-211708" for the manually recorded progesterone data, and the Cooperative Cattle Improvement Organization CRV BV (Arnhem, the Netherlands) for providing the pedigree data for this study. A. M. M. Tenghe benefited from a joint grant from the European Commission and the European Union Seventh Framework Programme (FP7/ 2007-2013) under the grant agreement $n^{\circ} 311776$, within the framework of the Erasmus-Mundus joint doctorate "EGS-ABG" (Paris, France). This study was performed as part of the Prolific project. The Prolific project is financially supported by the European Commission under the Seventh Research Framework Programme, Grant Agreement n³11776.

\section{REFERENCES}

Ashburner, M., C. A. Ball, J. A. Blake, D. Botstein, H. Butler, J M. Cherry, A. P. Davis, K. Dolinski, S. S. Dwight, and J. T. Eppig. 2000. Gene Ontology: Tool for the unification of biology. Nat. Genet. 25:25-29.

Berry, D. P., J. W. M. Bastiaansen, R. F. Veerkamp, S. Wijga, E. Wall, B. Berglund, and M. P. L. Calus. 2012. Genome-wide associations for fertility traits in Holstein-Friesian dairy cows using data from experimental research herds in four European countries. Animal 6:1206-1215.

Berry, D. P., F. Buckley, P. Dillon, R. D. Evans, M. Rath, and R. F. Veerkamp. 2003. Genetic relationships among body condition score, body weight, milk yield, and fertility in dairy cows. J. Dairy Sci. 86:2193-2204.

Bouwman, A. C., and R. F. Veerkamp. 2014. Consequences of splitting whole-genome sequencing effort over multiple breeds on imputation accuracy. BMC Genet. 15:105.

Browning, B. L., and S. R. Browning. 2009. A unified approach to genotype imputation and haplotype-phase inference for large data sets of trios and unrelated individuals. Am. J. Hum. Genet. $84: 210-223$.

Bulman, D. C., and G. E. Lamming. 1978. Milk progesterone levels in relation to conception, repeat breeding and factors influencing acyclicity in dairy cows. J. Reprod. Fertil. 54:447-458.

Campos, M. S., C. J. Wilcox, C. M. Becerril, and A. Diz. 1994. Genetic parameters for yield and reproductive traits of Holstein and Jersey cattle in Florida. J. Dairy Sci. 77:867-873.

Clark, S. A., J. M. Hickey, and J. H. J. Van der Werf. 2011. Different models of genetic variation and their effect on genomic evaluation. Genet. Sel. Evol. 43:18.

Conti, M., M. Hsieh, A. M. Zamah, and J. S. Oh. 2012. Novel signaling mechanisms in the ovary during oocyte maturation and ovulation. Mol. Cell. Endocrinol. 356:65-73.

Cunningham, F., M. R. Amode, D. Barrell, K. Beal, K. Billis, S. Brent, D. Carvalho-Silva, P. Clapham, G. Coates, S. Fitzgerald, L. Gil, C. G. Girón, L. Gordon, T. Hourlier, S. E. Hunt, S. H. Janacek, N. Johnson, T. Juettemann, A. K. Kähäri, S. Keenan, F. J. Martin, T. Maurel, W. McLaren, D. N. Murphy, R. Nag, B. Overduin, A. Parker, M. Patricio, E. Perry, M. Pignatelli, H. S. Riat, D. Sheppard, K. Taylor, A. Thormann, A. Vullo, S. P. Wilder, A. Zadissa, B. L. Aken, E. Birney, J. Harrow, R. Kinsella, M. Muffato, M. Ruffier, S. M. J. Searle, G. Spudich, S. J. Trevanion, A. Yates, D. R. Zerbino, and P. Flicek. 2015. Ensembl 2015. Nucleic Acids Res. 43:D662-D669. 
da Silveira, J. C., E. M. Carnevale, Q. A. Winger, and G. J. Bouma. 2014. Regulation of ACVR1 and ID2 by cell-secreted exosomes during follicle maturation in the mare. Reprod. Biol. Endocrinol. $12: 44$

Daetwyler, H. D., A. Capitan, H. Pausch, P. Stothard, R. Van Binsbergen, R. F. Brøndum, X. Liao, A. Djari, S. C. Rodriguez, C. Grohs, D. Esquerré, O. Bouchez, M.-N. Rossignol, C. Klopp, D. Rocha, S. Fritz, A. Eggen, P. J. Bowman, D. Coote, A. J. Chamberlain, C. Anderson, C. P. VanTassell, I. Hulsegge, M. E. Goddard, B. Guldbrandtsen, M. S. Lund, R. F. Veerkamp, D. A. Boichard, R. Fries, and B. J. Hayes. 2014. Whole-genome sequencing of 234 bulls facilitates mapping of monogenic and complex traits in cattle. Nat. Genet. 46:858-865.

Darwash, A. O., G. L. Ward, G. E. Lamming, and J. A. Woolliams. 1999. The effects of raising post-oestrus progesterone concentrations on luteal activity in post-partum dairy cows. Anim. Sci. $68: 527-532$.

Druet, T., S. Fritz, M. Boussaha, S. Ben-Jemaa, F. Guillaume, D. Derbala, D. Zelenika, D. Lechner, C. Charon, D. Boichard, I. G. Gut, A. Eggen, and M. Gautier. 2008. Fine mapping of quantitative trait loci affecting female fertility in dairy cattle on BTA03 using a dense single-nucleotide polymorphism map. Genetics 178:22272235 .

Druet, T., I. M. Macleod, and B. J. Hayes. 2014. Toward genomic prediction from whole-genome sequence data: Impact of sequencing design on genotype imputation and accuracy of predictions. Heredity (Edinb.) 112:39-47.

Edson, M. A., A. K. Nagaraja, and M. M. Matzuk. 2009. The mammalian ovary from genesis to revelation. Endocr. Rev. 30:624-712.

Fang, M., W. Fu, D. Jiang, Q. Zhang, D. Sun, X. Ding, and J. Liu. 2014. A multiple-SNP approach for genome-wide association study of milk production traits in Chinese Holstein cattle. PLoS ONE 9:e99544.

Friggens, N. C., M. Bjerring, C. Ridder, S. Højsgaard, and T. Larsen. 2008. Improved detection of reproductive status in dairy cows using milk progesterone measurements. Reprod. Domest. Anim. 43(Suppl. 2):113-121.

Fuchsberger, C., G. R. Abecasis, and D. A. Hinds. 2015. minimac2: Faster genotype imputation. Bioinformatics 31:782-784.

Geer, L. Y., A. Marchler-Bauer, R. C. Geer, L. Han, J. He, S. He, C. Liu, W. Shi, and S. H. Bryant. 2010. The NCBI BioSystems database. Nucleic Acids Res. 38:D492-D496.

Gilmour, A. R., B. J. Gogel, B. R. Cullis, S. J. Welham, and R. Thompson. 2014. ASReml User Guide Release 4.1 Structural Specification, VSN International Ltd., Hemel Hempstead, UK. www. vsni.co.uk.

Glister, C., L. Satchell, and P. G. Knight. 2010. Changes in expression of bone morphogenetic proteins (BMPs), their receptors and inhibin co-receptor betaglycan during bovine antral follicle development: Inhibin can antagonize the suppressive effect of BMPs on thecal androgen production. Reproduction 140:699-712.

Goddard, M. E., B. J. Hayes, and T. H. E. Meuwissen. 2010. Genomic selection in livestock populations. Genet. Res. (Camb.) 92:413-421.

Hayes, B. J., P. J. Bowman, A. J. Chamberlain, and M. E. Goddard. 2009. Invited review: Genomic selection in dairy cattle: Progress and challenges. J. Dairy Sci. 92:433-443.

Hayes, B. J., A. MacLeod, H. D. Daetwyler, R. F. Veerkamp, C. Tassell, B. Gredler, T. Druet, A. Bagnato, J. Vilkki, and D. J. de Koning. 2014. Genomic prediction from whole genome sequence in Livestock: 1000 bull genomics project. In Proc. of the 10th World Congress of Genetics Applied to Livestock Production. 17-22 August 2014; Vancouver. 2014. https://asas.org/docs/ default-source/wcgalp-proceedingsoral/183_paper_10441_ manuscript_1644_0.pdf.

Höglund, J. K., B. Guldbrandtsen, M. S. Lund, and G. Sahana. 2015. Identification of genomic regions associated with female fertility in Danish Jersey using whole genome sequence data. BMC Genet. 16:60.

Höglund, J. K., G. Sahana, R. Brøndum, B. Guldbrandtsen, B. Buitenhuis, and M. S. Lund. 2014a. Fine mapping QTL for female fertility on BTA04 and BTA13 in dairy cattle using HD SNP and sequence data. BMC Genomics 15:790.

Höglund, J. K., G. Sahana, B. Guldbrandtsen, and M. S. Lund. 2014b. Validation of associations for female fertility traits in Nordic Holstein, Nordic Red and Jersey dairy cattle. BMC Genet. 15:8.

Horan, B., J. F. Mee, P. O'Connor, M. Rath, and P. Dillon. 2005. The effect of strain of Holstein-Friesian cow and feeding system on postpartum ovarian function, animal production and conception rate to first service. Theriogenology 63:950-971.

Hu, Z.-L., C. A. Park, and J. M. Reecy. 2016. Developmental progress and current status of the Animal QTLdb. Nucleic Acids Res. 44:D827-D833.

Karlsson, E. K., I. Baranowska, C. M. Wade, N. H. C. S. Hillbertz, M. C. Zody, N. Anderson, T. M. Biagi, N. Patterson, G. R. Pielberg, and E. J. Kulbokas. 2007. Efficient mapping of mendelian traits in dogs through genome-wide association. Nat. Genet. 39:1321-1328.

Kemper, K. E., D. L. Emery, S. C. Bishop, H. Oddy, B. J. Hayes, S. Dominik, J. M. Henshall, and M. E. Goddard. 2011. The distribution of SNP marker effects for faecal worm egg count in sheep, and the feasibility of using these markers to predict genetic merit for resistance to worm infections. Genet. Res. (Camb.) 93:203-219.

Khatkar, M. S., P. C. Thomson, I. Tammen, and H. W. Raadsma. 2004. Quantitative trait loci mapping in dairy cattle: Review and meta-analysis. Genet. Sel. Evol. 36:163-190.

Knight, P. G., and C. Glister. 2006. TGF- $\beta$ superfamily members and ovarian follicle development. Reproduction 132:191-206.

Landim-Alvarenga, F. C., and R. R. D. Maziero. 2014. Control of oocyte maturation. Anim. Reprod. 11:150-158.

Li, H., B. Handsaker, A. Wysoker, T. Fennell, J. Ruan, N. Homer, G. Marth, G. Abecasis, and R. Durbin. 2009. The sequence alignment/map format and SAMtools. Bioinformatics 25:2078-2079.

Meuwissen, T., and M. Goddard. 2010. Accurate prediction of genetic values for complex traits by whole-genome resequencing. Genetics 185:623-631.

Nyman, S., K. Johansson, D. J. de Koning, D. P. Berry, R. F. Veerkamp, E. Wall, and B. Berglund. 2014. Genetic analysis of atypical progesterone profiles in Holstein-Friesian cows from experimental research herds. J. Dairy Sci. 97:7230-7239.

Ober, U., J. F. Ayroles, E. A. Stone, S. Richards, D. Zhu, R. A. Gibbs, C. Stricker, D. Gianola, M. Schlather, and T. F. C. Mackay. 2012. Using whole-genome sequence data to predict quantitative trait phenotypes in Drosophila melanogaster. PLoS Genet. 8:e1002685.

Petersson, K.-J., B. Berglund, E. Strandberg, H. Gustafsson, A. P. F. Flint, J. A. Woolliams, and M. D. Royal. 2007. Genetic analysis of postpartum measures of luteal activity in dairy cows. J. Dairy Sci. 90:427-434

Petersson, K.-J., E. Strandberg, H. Gustafsson, and B. Berglund. 2006. Environmental effects on progesterone profile measures of dairy cow fertility. Anim. Reprod. Sci. 91:201-214.

Pollott, G. E., and M. P. Coffey. 2008. The effect of genetic merit and production system on dairy cow fertility, measured using progesterone profiles and on-farm recording. J. Dairy Sci. 91:3649-3660.

Pruim, R. J., R. P. Welch, S. Sanna, T. M. Teslovich, P. S. Chines, T. P. Gliedt, M. Boehnke, G. R. Abecasis, and C. J. Willer. 2010. LocusZoom: regional visualization of genome-wide association scan results. Bioinformatics 26:2336-2337.

Pryce, J. E., R. J. Esslemont, R. Thompson, R. F. Veerkamp, M. A. Kossaibati, and G. Simm. 1998. Estimation of genetic parameters using health, fertility and production data from a management recording system for dairy cattle. Anim. Sci. 66:577-584.

Sahana, G., B. Guldbrandtsen, C. Bendixen, and M. S. Lund. 2010 Genome-wide association mapping for female fertility traits in Danish and Swedish Holstein cattle. Anim. Genet. 41:579-588.

Sahana, G., B. Guldbrandtsen, B. Thomsen, L. E. Holm, F. Panitz, R. F. Brøndum, C. Bendixen, and M. S. Lund. 2014. Genomewide association study using high-density single nucleotide polymorphism arrays and whole-genome sequences for clinical mastitis traits in dairy cattle. J. Dairy Sci. 97:7258-7275.

Sela-Abramovich, S., I. Edry, D. Galiani, N. Nevo, and N. Dekel. 2006. Disruption of gap junctional communication within the ovarian follicle induces oocyte maturation. Endocrinology 147:2280-2286. 
Shimizu, T., B. C. Jayawardana, H. Nishimoto, E. Kaneko, M. Tetsuka, and A. Miyamoto. 2006. Involvement of the bone morphogenetic protein/receptor system during follicle development in the bovine ovary: Hormonal regulation of the expression of bone morphogenetic protein 7 (BMP-7) and its receptors (ActRII and ALK-2). Mol. Cell. Endocrinol. 249:78-83.

Stahl, E. A., D. Wegmann, G. Trynka, J. Gutierrez-Achury, R. Do, B. F. Voight, P. Kraft, R. Chen, H. J. Kallberg, and F. A. S. Kurreeman. 2012. Bayesian inference analyses of the polygenic architecture of rheumatoid arthritis. Nat. Genet. 44:483-489.

Su, G., R. F. Brøndum, P. Ma, B. Guldbrandtsen, G. P. Aamand, and M. S. Lund. 2012. Comparison of genomic predictions using medium-density $(\sim 54,000)$ and high-density $(\sim 777,000)$ single nucleotide polymorphism marker panels in Nordic Holstein and Red Dairy Cattle populations. J. Dairy Sci. 95:4657-4665.

Tenghe, A. M. M., A. C. Bouwman, B. Berglund, E. Strandberg, J. Y. Blom, and R. F. Veerkamp. 2015. Estimating genetic parameters for fertility in dairy cows from in-line milk progesterone profiles. J. Dairy Sci. 98:5763-5773.

Teyssèdre, S., M. C. Dupuis, G. Guérin, L. Schibler, J. M. Denoix J. M. Elsen, and A. Ricard. 2012. Genome-wide association studies for osteochondrosis in French Trotter horses. J. Anim. Sci. 90:45-53.

van Binsbergen, R., M. P. L. Calus, M. C. A. M. Bink, F. A. van Eeuwijk, C. Schrooten, and R. F. Veerkamp. 2015. Genomic prediction using imputed whole-genome sequence data in Holstein Friesian cattle. Genet. Sel. Evol. 47:71.
VanRaden, P. M., D. J. Null, M. Sargolzaei, G. R. Wiggans, M. E. Tooker, J. B. Cole, T. S. Sonstegard, E. E. Connor, M. Winters, and J. van Kaam. 2013. Genomic imputation and evaluation using high-density Holstein genotypes. J. Dairy Sci. 96:668-678.

VanRaden, P. M., A. H. Sanders, M. E. Tooker, R. H. Miller, H. D. Norman, M. T. Kuhn, and G. R. Wiggans. 2004. Development of a national genetic evaluation for cow fertility. J. Dairy Sci. 87:2285-2292.

Veerkamp, R. F., J. K. Oldenbroek, H. J. Van Der Gaast, and J. H. J. Van Der Werf. 2000. Genetic correlation between days until start of luteal activity and milk yield, energy balance, and live weights. J. Dairy Sci. 83:577-583.

Wellcome Trust Case Control Consortium. 2007. Genome-wide association study of 14,000 cases of seven common diseases and 3,000 shared controls. Nature 447:661-678.

Wiggans, G. R., P. M. VanRaden, and T. A. Cooper. 2011. The genomic evaluation system in the United States: Past, present, future. J. Dairy Sci. 94:3202-3211.

Zhao, H., Z. Li, A. J. Cooney, and Z.-J. Lan. 2007. Orphan nuclear receptor function in the ovary. Front. Biosci. 12:3398-3405.

Zimin, A. V., A. L. Delcher, L. Florea, D. R. Kelley, M. C. Schatz, D. Puiu, F. Hanrahan, G. Pertea, C. P. Van Tassell, and T. S. Sonstegard. 2009. A whole-genome assembly of the domestic cow, Bos taurus. Genome Biol. 10:R42. 